\title{
Chamber inhibitors of steel corrosion based on lauric acid
}

\author{
I.V. Tsvetkova, ${ }^{1,2}$ A.Yu. Luchkin, ${ }^{1}{ }^{10}$ O.A. Goncharova, ${ }^{1}$ S.S. Veselyi ${ }^{1}$ \\ and N.N. Andreev ${ }^{1}$ (D) \\ ${ }^{1}$ A.N. Frumkin Institute of Physical Chemistry and Electrochemistry, Russian Academy \\ of Sciences, Leninsky pr. 31, 119071 Moscow, Russian Federation \\ ${ }^{2}$ D. Mendeleev University of Chemical Technology of Russia, Miusskaya sq. 9, 125047 \\ Moscow, Russian Federation \\ *E-mail: $\underline{\text { n.andreev@mail.ru }}$
}

\begin{abstract}
Chamber protection is a kind of vapor-phase protection of metals from atmospheric corrosion by means of corrosion inhibitors. It involves short-term treatment of metals in inhibitor vapors at elevated temperatures and is based on the anticorrosive aftereffect of the adsorption films formed in this process. The use of chamber inhibitors is a promising approach to the in-process steel protection. The ability of lauric acid, its binary mixtures with urotropine, as well as ternary mixtures with urotropine and benzotriazole, tolyltriazole or chlorobenzotriazole to protect steel in chamber protection was studied by a combination of electrochemical and corrosion methods. It has been shown that lauric acid itself is an efficient chamber inhibitor of atmospheric corrosion. Its protective effect can be enhanced by addition of urotropine or combinations of urotropine with benzotriazole or its derivatives. The protective effect of the mixed chamber inhibitors that we studied significantly exceeds that of their components. Nevertheless, analysis of the mutual effect of the components indicates that they do not manifest synergistic interactions.
\end{abstract}

Keywords: atmospheric corrosion, chamber inhibitors, lauric acid, vapor-phase protection of steel.

Received: December 10, 2020. Published: February 2, 2021

doi: $\underline{10.17675 / 2305-6894-2021-10-1-6}$

\section{Introduction}

As a rule, the production of complex metal items is a process involving many intermediate operations. Oftentimes, this process is not continuous and involves the in-process storage of semi-finished metal products [1,2]. Storage of this kind requires special measures to protect metals from corrosion. According to the recommendations of the Russian Federation standard [3], if products need to be stored for a period longer than 4-6 hours after machining, temporary anti-corrosion protection is required. Immediate corrosion protection is required after pickling, electrochemical machining, vibration abrasive blasting, wet abrasive blasting, chemical branding, treatment in salt baths, and similar operations. If corrosion protection is neglected, products can begin to corrode with reversible and/or irreversible formation of defects that may cause economic and reputational losses of the production enterprises. 
Inhibitors are widely used for the temporary protection of metals from atmospheric corrosion $[4,5]$. They are subdivided into contact inhibitors and vapor phase inhibitors. Preservation is performed by applying contact inhibitors on the surface in the form of an active compound, its solutions, or within specialized oils, greases, mastics, and other materials. Vapor-phase inhibitors reach the surface of metals spontaneously as vapors. In the case of the most common type of vapor-phase inhibitors, i.e., volatile inhibitors (VCIs), the compound itself can serve as the inhibitor source, for example, in tablets, on special porous carriers, as a wrapping paper or film [6-11].

In fact, the use of a VCI is justified whenever it is feasible to seal the space to be protected. However, the need to pack a VCI together with the metal items to be protected for the entire protection period significantly limits the use of inhibitors of this type and is one of their main drawbacks.

Another class of vapor-phase inhibitors, chamber inhibitors (CIN), lacks this drawback. The protection of metal items involves just a short-term treatment of the metals in inhibitor vapors at elevated temperatures [12-14]. Chamber treatment (CT) creates nanoscale films with a long protective aftereffect on the metal surface.

Chamber treatment features economical efficiency and environmental friendliness. The consumption of an active compound for CT is very small. Moreover, chamber treatment does not produce permanent wastes such as wash water, spent or contaminated solutions, or usedup inhibited packaging materials. It is significant that during preservation, a CIN is only located in the working chamber and does not come into direct contact with persons engaged in anti-corrosion protection operations or with the environment.

We have shown in our studies that the chamber treatment method can provide efficient protection of various metals and alloys from atmospheric corrosion [12-20].

The purpose of this work was to estimate the feasibility of creating an efficient composite chamber inhibitor for carbon steel based on lauric acid (LA). It should be noted that, on the one hand, lauric acid belongs to environmentally friendly compounds, and on the other hand, higher carboxylic acids proved to be efficient inhibitors of steel corrosion [15]. Urotropine (UR) and compounds of the benzotriazole class, namely 1,2,3-1H-

benzotriazole (BTA) itself, tolyltriazole (TTA), and 5-chloro-1,2,3-1H-benzotriazole (CBTA), were considered as additives that might enhance the protective effect of lauric acid.

\section{Experimental}

\subsection{Samples and electrodes}

Samples and electrodes made of St3 steel were used in the studies. The steel composition matches the corresponding standard [22].

The flat specimens intended for corrosion tests had dimensions of $30 \times 50 \times 3 \mathrm{~mm}$. Each specimen had a hole for mounting in test cells and chambers. Cylindrical electrodes were $10 \mathrm{~mm}$ in diameter. One of their cross-cuts had a hole with threading for a mounting rod. 
Electrodes were embedded in Teflon casings in order to protect their side surfaces from interaction with the electrolyte during the tests. The lower cross-cut of a cylinder served as the working surface.

Before the experiments, the working surfaces of the samples and electrodes were cleaned with sandpaper of various grain sizes, degreased with acetone, thoroughly washed with water, and dried.

Samples and electrodes prepared as described above were mounted in sealed glass vessels with a capacity of 0.6 liters containing a weighed amount of a CIN $(0.5 \mathrm{~g})$ or without it. The vessels were placed in a SNOL 50/350 drying oven heated to $120^{\circ} \mathrm{C}$. The metal treatment time was $1 \mathrm{~h}$. In accordance with $[13,15]$, this temperature and CT duration is sufficient for the formation of protective adsorption films on steel. After exposure in the drying oven, the vessels were removed and cooled to room temperature. The samples and electrodes were removed from the atmosphere containing the CIN vapors and kept for 24 hours under ambient conditions.

\subsection{Electrochemical studies}

\subsubsection{Voltammetric tests}

Voltammetric experiments were performed using an IPC-pro potentiostat (Russian Federation) and a standard three-electrode cell with divided electrode spaces. A platinum wire served as the auxiliary electrode. The potentials $(E)$ were measured against a saturated silver/silver chloride reference electrode and converted to the normal hydrogen scale. Experiments were carried out in borate buffer solution ( $\mathrm{pH} 7.36$ ) containing $0.001 \mathrm{M}$ sodium chloride. Electrodes were placed in a cell with the electrolyte, kept for $5 \mathrm{~min}$, and polarized anodically from the established potential $\left(E_{0}\right)$ at a sweep rate of $0.2 \mathrm{mV} / \mathrm{s}$. The protective properties of CIN were characterized by pitting potentials $\left(E_{\mathrm{pt}}\right)$, breakdown potentials $\left(E_{\mathrm{br}}\right)$, and anti-pitting basis $\left(\Delta E=E_{\mathrm{pt}}-E_{0}\right) . E_{\mathrm{pt}}$ was determined as the potential at which current oscillations appeared on the polarization curves or as $E_{\mathrm{br}}$ if no oscillations were observed. $E_{\mathrm{br}}$ was determined as the potential where the anodic current density $(i)$ reached $5 \mu \mathrm{A} / \mathrm{cm}^{2}$.

\subsubsection{Electrochemical impedance spectroscopy}

Electrochemical impedance spectra were recorded using a potentiostat of the same brand and a frequency response analyzer (FRA) manufactured in the Russian Federation. The experiments were carried out using a cell, electrodes, and conditions similar to those used in the polarization experiments. The frequency was varied from 0.1 to $10^{5} \mathrm{~Hz}$. Electrochemical impedance parameters were calculated using the equivalent circuit that is widely used for various metals and alloys [15-19]: 


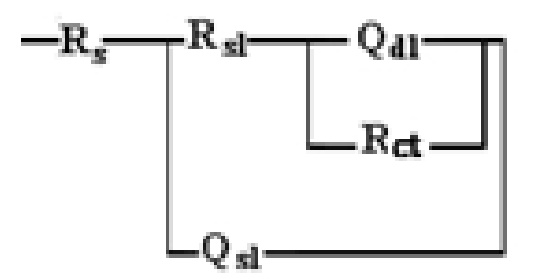

where $R_{\mathrm{S}}$ is the resistance of the bulk electrolyte between the auxiliary and working electrodes that does not affect the electrode processes and depends on the conductivity of the medium and the cell geometry; $R_{\mathrm{sl}}$ is the resistance of the surface layers (oxide-hydroxide and adsorption ones); $R_{\mathrm{ct}}$ is the polarization resistance characterizing the electrochemical kinetics of the corrosion process; $Q_{\mathrm{sl}}$ is the constant phase element characterizing the capacitance of surface oxide-hydroxide layers and/or adsorption layers; and $Q_{\mathrm{dl}}$ is the constant phase element that reflects the capacitance of the double electric layer. The impedance of the constant phase element was described by the equation:

$$
Z_{Q}=A^{-1}(j \omega)^{-n},
$$

where $A$ is the proportionality factor; $j$ is the imaginary unit; $\omega$ is the complex frequency associated with the alternating current frequency; and $n$ is an exponential phase deviation indicator, $0 \leq|m| \leq 1$.

The results were processed to determine the equivalent circuit parameters using Dummy Circuits Solver software, version 2.1. The fit between experimental and calculated data was no worse than $98 \%$.

The degree of steel electrode protection was calculated by the formula:

$$
Z=\frac{R_{\text {inh }}-R_{\mathrm{bg}}}{R_{\text {inh }}} \cdot 100 \%,
$$

where $R_{\mathrm{bg}}$ and $R_{\mathrm{inh}}$ is the total resistance of the "steel-electrolyte" interphase interaction that includes $R_{\mathrm{ct}}$ and $R_{\mathrm{sl}}$ after thermal treatment (TT) of the electrode in the absence and in the presence of CIN, respectively.

\subsection{Corrosion tests}

The protective aftereffect (PAE) of the surface layers formed upon CT was estimated under conditions of $100 \%$ relative humidity and recurrent moisture condensation. The samples were mounted by polymer hooks to the lids of sealed glass cells so as to prevent their contact with each other and with the cell walls. The volume of each cell was $0.6 \mathrm{~L}$. Hot water $(0.15 \mathrm{~L}$, $50^{\circ} \mathrm{C}$ ) was poured into each cell, which caused abundant moisture condensation on the samples. After that, the cells were placed into a SNOL 50/350 thermostatic cabinet where the following daily temperature conditions were maintained: $40^{\circ} \mathrm{C}$ for $8 \mathrm{~h}$ and $20^{\circ} \mathrm{C}$ for $16 \mathrm{~h}$. The samples were visually examined without opening the cells every hour for two days from the beginning of the tests and every 6 hours in subsequent days. The time $(\tau)$ until corrosion damage appeared on the metal was recorded. 


\section{Results and Discussion}

\subsection{Electrochemical studies}

\subsubsection{Voltammetric tests}

The anodic polarization curves of steel samples before and after the treatment have a shape characteristic of the passive metal (Figure 1).

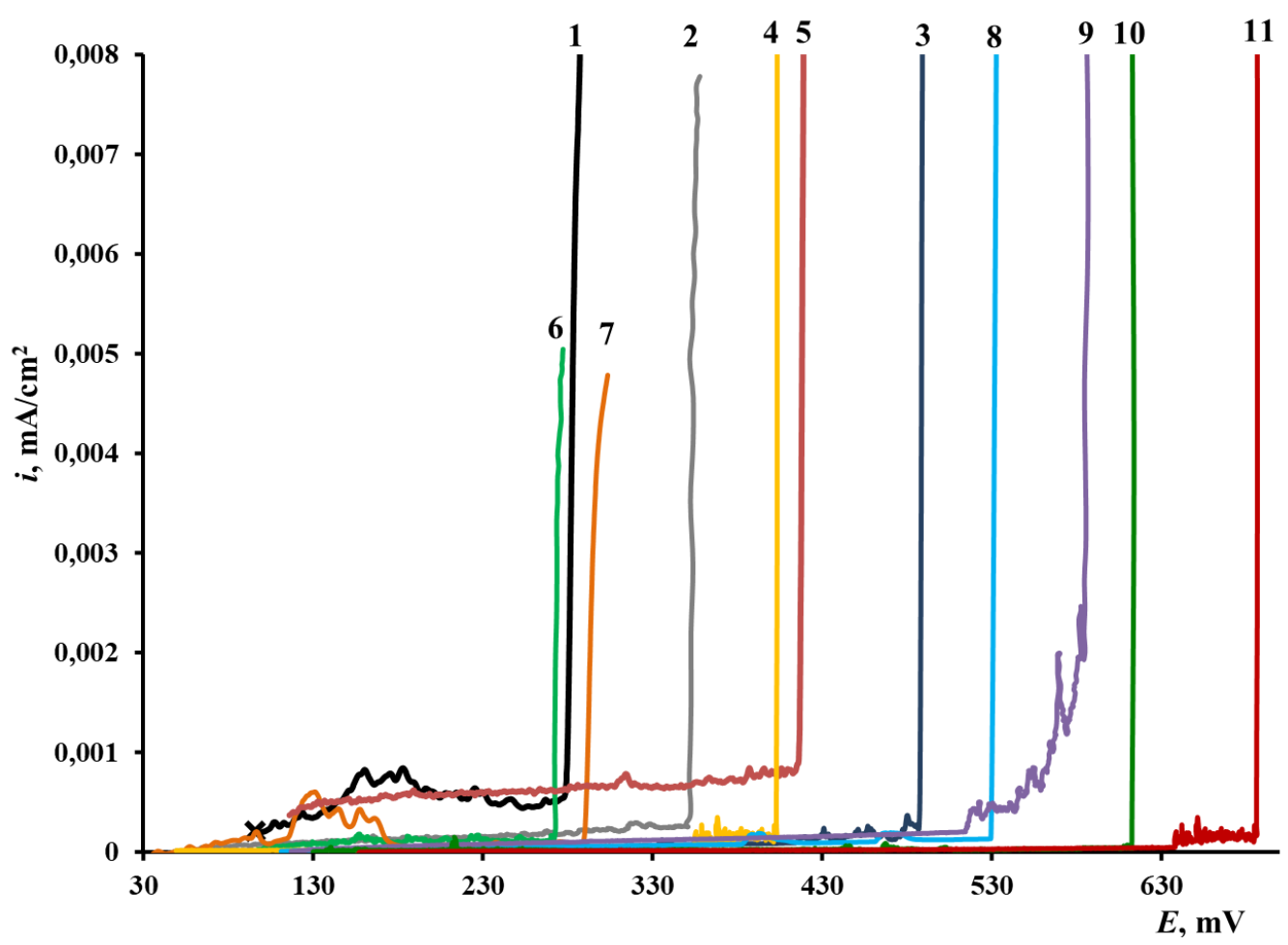

Figure 1. Anodic polarization curves of a steel electrode before (1) and after TT without a CIN (2), as well as in the presence of LA (3); UR (4); LA+UR (5); BTA (6); TTA (7); CBTA (8); LA+UR+BTA (9); LA+UR+TTA (10); LA+UR+CBTA (11).

The $E_{0}$ value for a background sample was about $0.1 \mathrm{~V}$. Almost immediately after the beginning of the anodic potential sweep, current oscillations appeared on the polarization curves, which can be interpreted as the local metal depassivation. The absence of a sharp increase in $i$ at this point is apparently associated with repassivation of the emerging pits. Breakdown of the passive film was observed at $0.27 \mathrm{~V}$.

Thermal treatment of a steel sample without a CIN led to a decrease in $E_{0}$ and $E_{\mathrm{pt}}$ (Table 1). Despite this, $E_{\mathrm{br}}$ shifted in the anodic direction. The calculated $\Delta E$ value increased twofold, which can be explained by a growth of the surface oxide during TT.

Steel electrodes treated with LA vapors show an $E_{0}$ enrichment by $0.03 \mathrm{~V}$. The film formed in LA vapors significantly inhibits the anodic dissolution of steel. The metal remains passive up to $0.43 \mathrm{~V}$. Upon reaching this potential, $i$ oscillations appeared on the polarization 
curves. The $E_{\mathrm{br}}$ of the protective film was about $0.49 \mathrm{~V}$. The $\Delta E$ value in this variant of steel chamber treatment was $0.30 \mathrm{~V}$.

Urea, which significantly increases the efficiency of higher carboxylic acids in chamber treatment [15], was considered as a component that enhances the protective effect of LA. The adsorption film obtained in UR vapors had almost no effect on the $E_{0}$ value. It was close to that recorded on the background sample after TT. The $E$ value was in the range of $0.40-$ $0.45 \mathrm{~V}$. The anti-pitting basis was nearly the same as the $\Delta E$ for LA.

Table 1. Characteristic E values of the anodic polarization curves of steel after different variants of CT.

\begin{tabular}{ccccc}
\hline Metal treatment & $\boldsymbol{E}_{\mathbf{0}}, \mathbf{V}$ & $\boldsymbol{E}_{\mathbf{p t}}, \mathbf{V}$ & $\boldsymbol{E}_{\mathbf{b r}}, \mathbf{V}$ & $\boldsymbol{\Delta}, \mathbf{V}$ \\
\hline- & 0.10 & 0.12 & 0.27 & 0.02 \\
\hline TT without a CIN & 0.05 & 0.09 & 0.35 & 0.04 \\
\hline CT in LA vapors & 0.13 & 0.43 & 0.49 & 0.31 \\
\hline CT in UR vapors & 0.05 & 0.36 & 0.40 & 0.31 \\
\hline CT in BTA vapors & 0.12 & 0.13 & 0.42 & 0.01 \\
\hline CT in TTA vapors & 0.10 & 0.14 & 0.27 & 0.04 \\
\hline CT in CBTA vapors & 0.03 & 0.11 & 0.29 & 0.08 \\
\hline CT in vapors of the LA+UR mixture & 0.11 & 0.53 & 0.53 & 0.42 \\
\hline $\begin{array}{c}\text { CT in vapors of the LA+UR+BTA } \\
\text { mixture }\end{array}$ & 0.12 & 0.51 & 0.52 & 0.40 \\
\hline $\begin{array}{c}\text { CT in vapors of the LA+UR+TTA } \\
\text { mixture }\end{array}$ & 0.13 & 0.61 & 0.61 & 0.48 \\
\hline $\begin{array}{c}\text { CT in vapors of the LA+UR+CBTA } \\
\text { mixture }\end{array}$ & 0.15 & 0.64 & 0.68 & 0.49 \\
\hline \begin{tabular}{c} 
C \\
\hline
\end{tabular} & & & &
\end{tabular}

The benzotriazoles studied inhibited the anodic process to a smaller extent than LA and UR. The polarization curves of steel treated in the vapors of these compounds demonstrated smaller values of $E_{\mathrm{pt}}, E_{\mathrm{br}}$ and $\Delta E$. An exception was BTA itself, whose $E_{\mathrm{br}}(0.42 \mathrm{~V})$ was between the $E_{\mathrm{br}}$ values measured for LA and UR.

The film formed on the surface of a steel electrode in the vapors of a mixture of LA and UR significantly exceeded the individual compounds in terms of PAE and the $\Delta E$ they provided was 1.4 times greater than those of the components alone. In this case, the anodic curve showed no $i$ oscillations up to $E_{\mathrm{br}}$.

The protective properties of the mixture of LA and UR can be improved by adding TTA or CBTA. Ternary mixtures based on these benzotriazole derivatives significantly exceeded the binary mixture of LA+UR by all the criteria considered above. The formulation of $\mathrm{LA}+\mathrm{UR}+\mathrm{BTA}$ was somewhat inferior to the mixture of $\mathrm{LA}+\mathrm{UR}$, again in terms of all the protective characteristics. 
Nevertheless, polarization measurements indicate a significant superiority of all the mixtures studied in comparison with their constituents.

Additional information on the protective effect of CIN films can be obtained using electrochemical impedance spectroscopy.

\subsubsection{Electrochemical impedance spectroscopy}

The Bode and Nyquist plots of a steel electrode before chamber treatment are shown in Figure 2. According to the equivalent circuit used, the hodograph can be divided into 3 sections. The frequency range of $100,000-1,000 \mathrm{~Hz}$ characterizes the electrolyte $\left(R_{\mathrm{s}}\right)$; the range of $1000-10 \mathrm{~Hz}$ characterizes the surface film, i.e., the air-formed oxide $\left(R_{\mathrm{sl}}\right)$; while the low frequency region $(5-0.1 \mathrm{~Hz})$ corresponds to processes associated with the double electric layer $\left(R_{\mathrm{ct}}\right)$. According to the calculation results (Table 2$)$, the exponential factor for $Q_{\mathrm{sl}}$ is 0.75 . This indicates a heterogeneity of the surface oxide layer. The $n$ value for $Q_{\mathrm{dl}}$ equals 1 , which allows us to interpret the constant phase element of the double layer as a pure capacitance. In this case, there are no diffusion processes. The major contribution to the total corrosion resistance is made by $R_{\mathrm{sl}}$ whose value is 2 times higher than $R_{\mathrm{ct}}$.
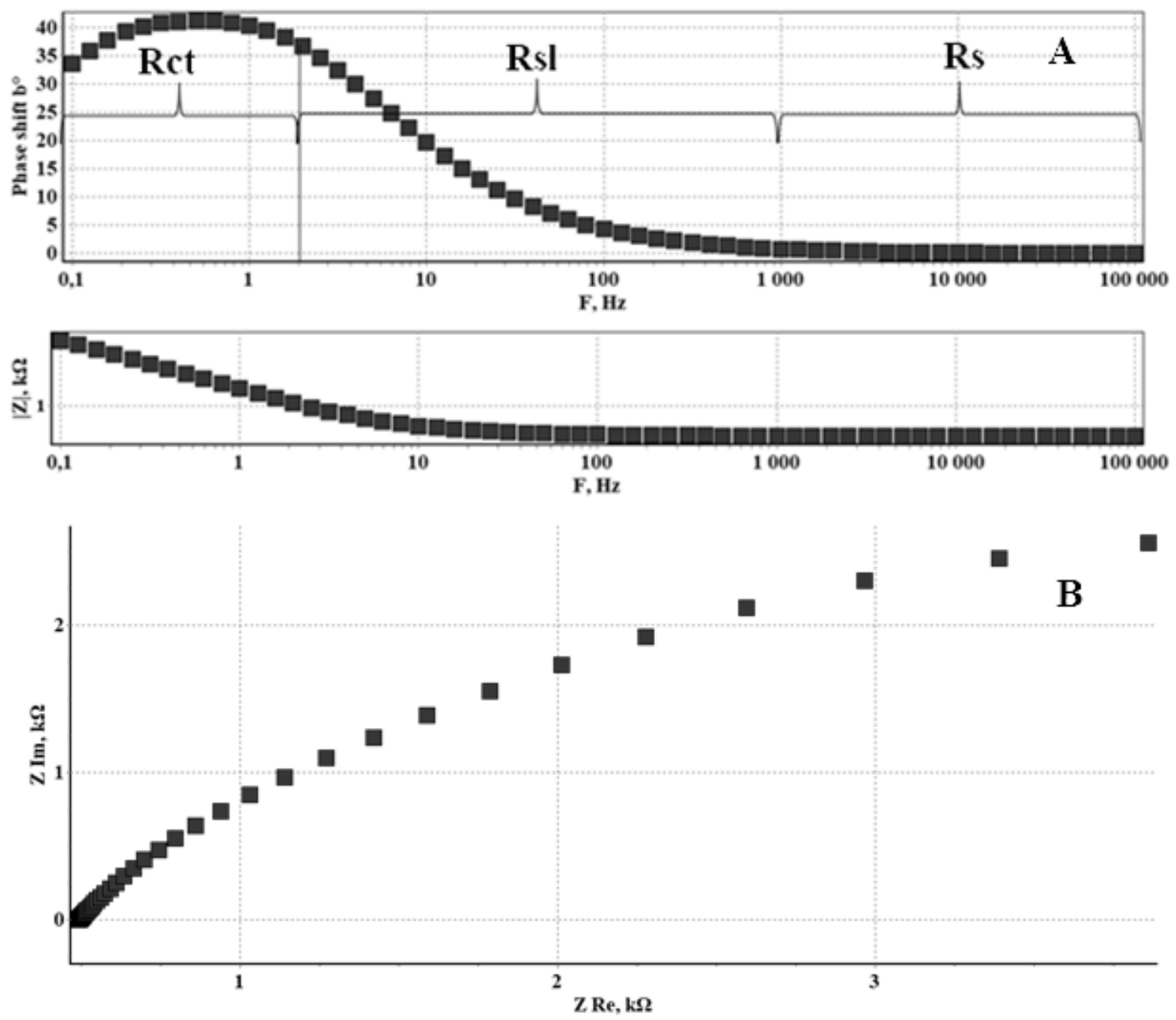

Figure 2. Bode (A) and Nyquist (B) plots of a steel electrode before TT. 
Table 2. Equivalent circuit parameters of steel electrodes treated in various ways.

\begin{tabular}{|c|c|c|c|c|c|c|c|c|}
\hline Metal treatment & $\begin{array}{c}R_{\mathrm{s}} \\
\mathrm{k} \Omega \cdot \mathrm{cm}^{2}\end{array}$ & $\underset{\mathrm{S} \mathrm{s} / \mathrm{sm}^{2}}{Q_{\mathrm{sl}}}$ & $n$ & $\begin{array}{c}R_{\mathrm{sl}} \\
\mathrm{k} \Omega \cdot \mathrm{cm}^{2}\end{array}$ & $\underset{\mathrm{S} \mathrm{s} \mathrm{s}^{n} / \mathrm{cm}^{2}}{Q_{\mathrm{dl}}}$ & $n$ & $\begin{array}{c}R_{\mathrm{ct}} \\
\mathrm{k} \Omega \cdot \mathrm{cm}^{2}\end{array}$ & $Z, \%$ \\
\hline- & 0.49 & $1.88 \cdot 10^{-4}$ & 0.75 & 5 & $3.01 \cdot 10^{-4}$ & 1 & 2.61 & \\
\hline TT without a CIN & 0.61 & $6.75 \cdot 10^{-5}$ & 0.87 & 11.8 & $5.46 \cdot 10^{-5}$ & 0.95 & 10.33 & 65.53 \\
\hline CT in LA vapors & 0.57 & $6.57 \cdot 10^{-6}$ & 0.85 & 73.13 & $2.00 \cdot 10^{-5}$ & 1 & 72.71 & 94.77 \\
\hline CT in UR vapors & 0.54 & $1.01 \cdot 10^{-5}$ & 1 & 16.31 & $3.64 \cdot 10^{-5}$ & 1 & 33.84 & 84.79 \\
\hline CT in BTA vapors & 0.39 & $5.64 \cdot 10^{-5}$ & 0.85 & 17.54 & $5.60 \cdot 10^{-5}$ & 1 & 15.55 & 76.85 \\
\hline CT in TTA vapors & 0.44 & $2.52 \cdot 10^{-5}$ & 1 & 8.71 & $4.76 \cdot 10^{-5}$ & 1 & 24.22 & 76.81 \\
\hline $\begin{array}{l}\mathrm{CT} \text { in CBTA } \\
\text { vapors }\end{array}$ & 0.46 & $1.90 \cdot 10^{-5}$ & 0.9 & 18.51 & $3.96 \cdot 10^{-5}$ & 0.86 & 32.81 & 85.14 \\
\hline $\begin{array}{l}\text { CT in vapors of the } \\
\text { LA+UR mixture }\end{array}$ & 0.53 & $2.80 \cdot 10^{-6}$ & 0.83 & 106.12 & $1.05 \cdot 10^{-5}$ & 1 & 142 & 96.93 \\
\hline $\begin{array}{c}\text { CT in vapors of the } \\
\mathrm{LA}+\mathrm{UR}+\mathrm{BTA} \\
\text { mixture }\end{array}$ & 0.44 & $1.44 \cdot 10^{-6}$ & 0.84 & 150.99 & $8.05 \cdot 10^{-6}$ & 1 & 229.51 & 97.99 \\
\hline $\begin{array}{l}\text { CT in vapors of the } \\
\mathrm{LA}+\mathrm{UR}+\mathrm{TTA} \\
\text { mixture }\end{array}$ & 0.74 & $5.83 \cdot 10^{-6}$ & 1 & 52.97 & $6.53 \cdot 10^{-6}$ & 1 & 259.11 & 97.56 \\
\hline $\begin{array}{c}\mathrm{CT} \text { in vapors of the } \\
\mathrm{LA}+\mathrm{UR}+\mathrm{CBTA} \\
\text { mixture }\end{array}$ & 0.76 & $4.06 \cdot 10^{-6}$ & 1 & 71.44 & $6.41 \cdot 10^{-6}$ & 1 & 320.26 & 98.05 \\
\hline
\end{tabular}

Thermal treatment of a steel electrode does not change the shape of the hodograph (Figure 3) but significantly increases the resistive characteristics of the electrode (Table 2). The increase in the charge transfer resistance is presumably associated with metal oxidation and a decrease in the electrochemically active area of the electrode surface. This is confirmed by a decrease in the $Q_{\mathrm{dl}}$ values. In this case, the inhomogeneity of the surface oxide film decreases somewhat $\left(n_{\mathrm{sl}}=0.87\right)$.

Chamber treatment in the vapors of individual CIN significantly increased the values of $R_{\mathrm{sl}}$ and $R_{\mathrm{ct}}$. However, the shape of the hodograph did not change much. The inhomogeneity of the surface layer decreased in comparison with the background. A significant increase in the complex resistance of the system for the samples treated in UR, TTA, or CBTA vapors was due to a significant increase in the $R_{\mathrm{ct}}$ values as compared to $R_{\mathrm{sl}}$. Upon CT of electrodes with LA and BTA, the contribution of $R_{\mathrm{ct}}$ and $R_{\mathrm{sl}}$ to the complex resistance was approximately the same. This may be due to the interaction of the CIN with surface oxides during the $\mathrm{CT}$ of the electrode. 


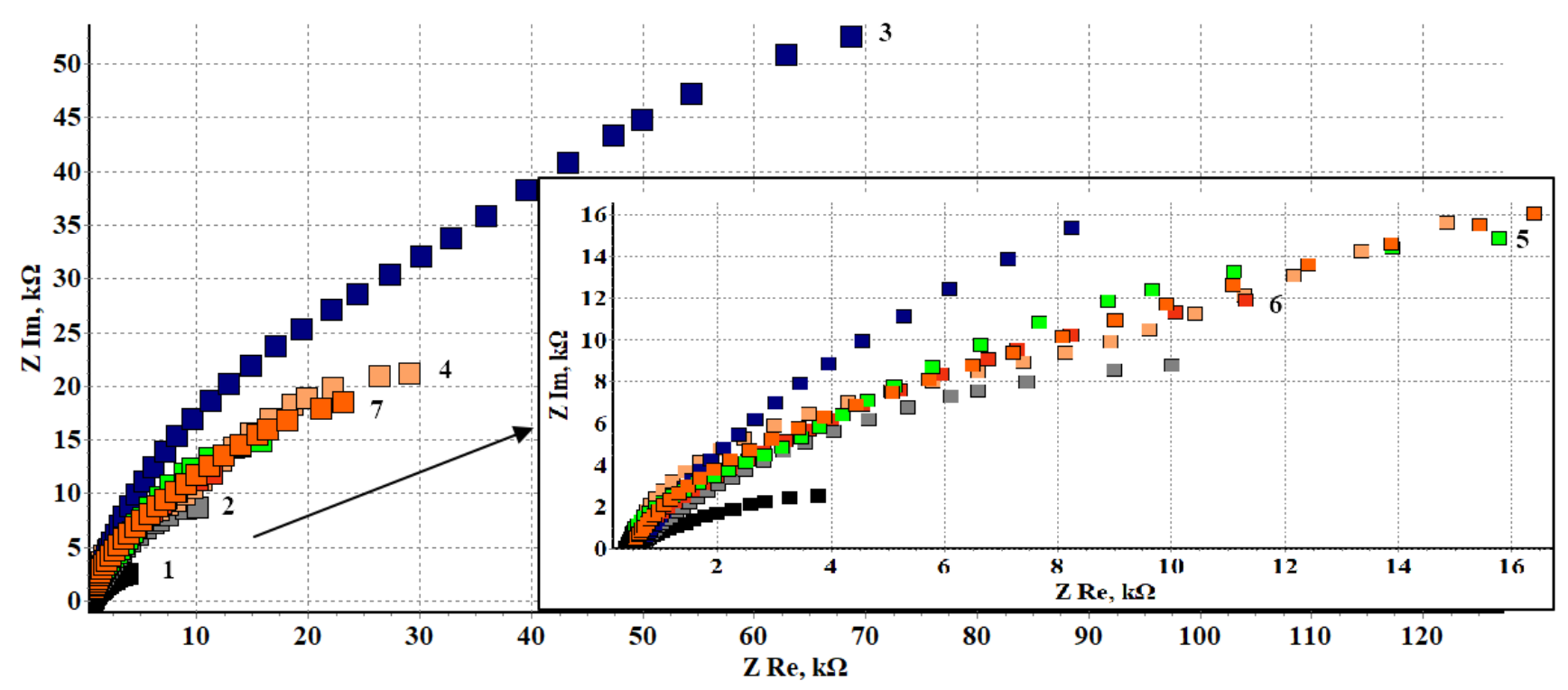

Figure 3. Nyquist plots of a steel electrode before-1 and after CT without -2 and in the presence of CIN: LA-3, UR-4, BTA-5, TTA-6, CBTA-7.

The values of $Q_{\mathrm{sl}}$ and $Q_{\mathrm{dl}}$ decreased significantly upon CT, which is a consequence of the adsorption of the CIN on the steel surface. $Q_{\mathrm{sl}}$ became virtually the pure capacitance for surface layers formed in UR and TTA vapors. In all the cases except for films formed in CBTA vapors, $Q_{\mathrm{dl}}$ was the pure capacitance of the double electric layer. Studies of CBTA films revealed a decrease in $n_{\mathrm{dl}}$ due to inhomogeneity of the oxide-inhibitor layer.

The films formed in vapors of mixed inhibitors whose Nyquist plots are shown in Figure 4 significantly exceed in protective aftereffect the adsorption films of individual components.

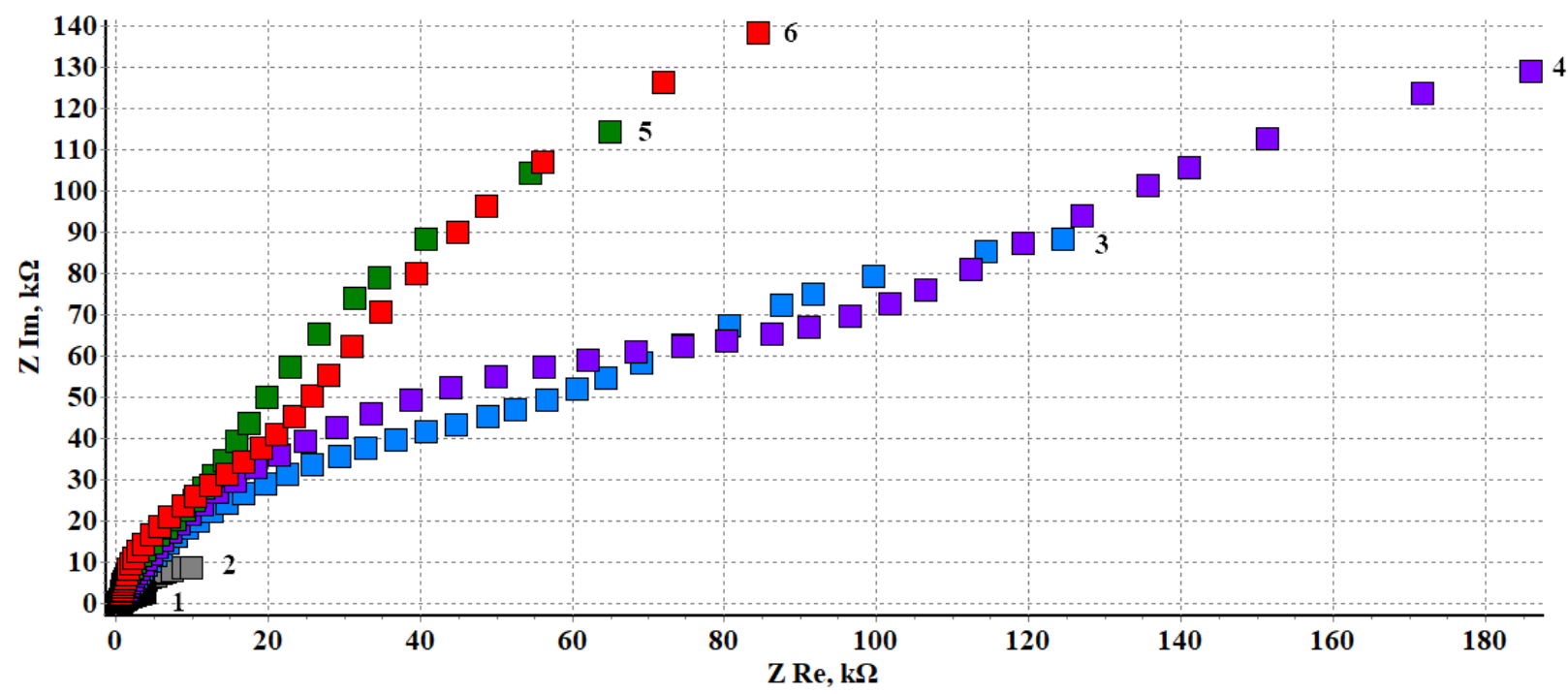

Figure 4. Nyquist plots of a steel electrodes before (1) and after CT in vapors of mixed CIN: CT without a CIN (2), LA+UR (3), LA+UR+BTA (4), LA+UR+TTA (5), LA+UR+CBTA (6). 
On all the hodographs, the sections responsible for surface layers and polarization resistance became more pronounced. The film formed in the vapors of the binary mixture is 1.7 times more efficient than the LA film and 4.8 times more efficient than the UR film. In this case, the main contribution to the complex resistance is made by $R_{\mathrm{ct}}$, which is 1.3 times higher than $R_{\mathrm{sl}}$.

Addition of triazoles to the binary mixture increased its efficiency significantly. $R_{\mathrm{sl}}$ increased in the series of mixtures: $\mathrm{LA}+\mathrm{UR}+\mathrm{TTA}<\mathrm{LA}+\mathrm{UR}+\mathrm{CBTA}<\mathrm{LA}+\mathrm{UR}+\mathrm{BTA}$. $R_{\mathrm{ct}}$ in ternary mixtures is significantly higher than $R_{\mathrm{sl}}$, while its increase in films of mixed CIN is similar to that in films of individual triazoles.

The conclusion about the superiority of ternary mixtures compared to the binary mixture and individual CIN is confirmed by the calculated $Z$ values.

For individual CIN, the $Z$ values did not exceed $94.7 \%$ as calculated for the most efficient LA. The $Z$ values for mixed inhibitors were higher than $96.9 \%$ demonstrated by the LA+UR binary mixture. The highest $\mathrm{Z}$ value $(98.1 \%)$ was obtained for the ternary mixture containing CBTA.

Thus, the results of impedance measurements well correlate with the voltammetric results. However, more accurate information on the protective properties of CIN films can be obtained using direct corrosion methods. In addition, corrosion experiments provide a quantitative estimate of the mutual effect of the components of mixed inhibitors.

\subsection{Corrosion tests}

The results of corrosion tests of steel that underwent various surface treatments are presented in Table 3.

The first trace of corrosion on samples that did not undergo heat treatment was observed after exposure for half an hour under the experimental conditions. CT without a CIN did not affect the corrosion resistance of steel. In both cases, general corrosion was observed.

CT in LA vapors increased the full protection time 144-fold, i.e., to 72 hours. The traced of corrosion appeared as dark spots. It is noteworthy that their size did not increase for at least 2 weeks. UR, BTA and its derivatives (TTA and CBTA) insignificantly increased the full protection time compared to the background samples. After exposure of the metal for 2-4 hours under the experimental conditions, spots of corrosion products appeared on the metal surface. Their area increased over time. In the case of CBTA, dark spots appeared on the surface, and their number rapidly increased.

The LA+UR binary mixture protected steel samples much longer, providing full steel protection for 336 hours. The triple mixtures were even more efficient. In fact, the $\mathrm{LA}+\mathrm{UR}+\mathrm{BTA}$ formulation totally protected steel for 432 hours, while the LA+UR+TTA and LA+UR+HBTA mixtures did so for 744 and 864 hours, respectively.

Note that the protective properties of mixed CIN significantly exceeded those of their components. However, it seems that no synergistic interaction occurs here. We observed this phenomenon previously [19]. 
According to [21], if the protective properties of inhibitors are estimated on the basis of $\tau$, the conclusion on whether there is a synergistic interaction of the mixture components is based on the criterion:

$$
\tau_{\sum \text {,meas. }}>\tau_{\sum \text {,calc. }},
$$

where $\tau_{\Sigma \text {,meas. }}$ are the times of full metal protection with a mixed inhibitor determined

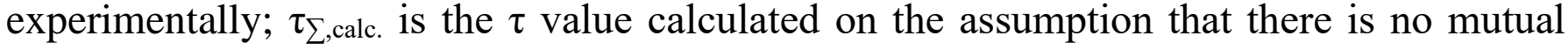
effect of the compounds in the $n$-component mixture; and $\tau_{\sum \text {,calc. is calculated by the formula: }}$

$$
\tau_{\sum \text {,calc }}=\tau_{1} \tau_{2} \ldots \tau_{n} / \tau_{0}^{n-1} .
$$

Here the $\tau_{1}, \tau_{2} \ldots \tau_{\mathrm{n}}$ values characterize the protective properties of individual compounds that constitute the $n$-component mixture and $\tau_{0}$ corresponds to the blank experiment.

As follows from the data in Table 3, the above inequality is not observed for the mixtures in question. The time of full steel protection with the LA+UR binary mixture is significantly shorter than the calculated value $\tau_{\Sigma \text {,calc. }}=\tau_{\mathrm{LA}} \tau_{\mathrm{UR}} / \tau_{0}$ (576 hours). The same is true for all the ternary mixtures.

Table 3. The time of full protection by individual $\mathrm{CIN}(\tau)$ and their mixtures $\left(\tau_{\Sigma, \text { meas }}\right)$ and the values of $\tau_{\Sigma \text {,calc. }}$ based on the assumption that there is no mutual effect of the mixed CIN components. meas.

\begin{tabular}{ccc}
\hline Metal treatment & $\boldsymbol{\tau}\left(\tau_{\Sigma}\right)$,meas., $\mathbf{h}$ & $\boldsymbol{\tau}_{\Sigma, \text { calc., }} \mathbf{h}$ \\
\hline- & 0.5 & - \\
\hline TT without a CIN & 0.5 & - \\
\hline CT in LA vapors & 72 & - \\
\hline CT in UR vapors & 4 & - \\
\hline CT in BTA vapors & 3 & - \\
\hline CT in TTA vapors & 4 & 376 \\
\hline CT in CBTA vapors & 2 & 3456 \\
\hline CT in vapors of LA+UR mixture & 336 & 4608 \\
\hline $\begin{array}{c}\text { CT in vapors of LA+UR+BTA } \\
\text { mixture }\end{array}$ & 432 & 2304 \\
\hline $\begin{array}{c}\text { CT in vapors of LA+UR+TTA } \\
\text { mixture }\end{array}$ & 744 & \\
\hline $\begin{array}{c}\text { CT in vapors of LA+UR+CBTA } \\
\text { mixture }\end{array}$ & 864 & - \\
\hline
\end{tabular}

Thus, the components of all the inhibitor mixtures in question not only lack a synergistic protective action but are even antagonistic to each other. Still, the protective aftereffect of the mixed CIN significantly exceeds that of their constituents. This again confirms the 
conclusion [21] that a synergistic interaction of the components is a desirable but not mandatory condition in the creation of efficient mixed inhibitors.

\section{Conclusions}

1. Lauric acid is an efficient chamber inhibitor of steel atmospheric corrosion.

2. The protective effect of lauric acid in the chamber protection of steel can be enhanced by addition of urotropine or a mixture of urotropine with benzotriazole or its derivatives, such as tolyltriazole or chlorobenzotriazole.

3. The protective effect of the mixed chamber inhibitors studied significantly exceeds that of their components. Nevertheless, analysis of the mutual effect of the components indicates that they have no synergistic interactions.

4. In the development of efficient mixed chamber inhibitors, the synergistic interaction of their components is desirable but not mandatory.

\section{References}

1. M.N. Kondrat'eva and E.V. Balandina, Economics and management of production, UlSTU, 2013 (in Russian).

2. V.I. Strazhev, Analysis of business activities in industry, Minsk, Vysshaya shkola, 2005 (in Russian).

3. GOST R 9.518-2006, Unified system for protection from corrosion and ageing (ESZKS). Inter-operation corrosion protection. General requirements (in Russian).

4. I.L. Rozenfel'd and V. P. Persiantseva, Ingibitory atmosfernoi korrozii (Inhibitors of atmospheric corrosion), Moscow, Nauka, 1985 (in Russian).

5. A.A. Mikhailov, Yu.M. Panchenko and Yu.I. Kuznetsov, Atmosfernaya korroziya i zashchita metallov (Atmospheric corrosion and protection of metals), Tambov, 2016, 554 pp. (in Russian).

6. N.N. Andreev, O.A. Goncharova and S.S. Vesely, Volatile inhibitors of atmospheric corrosion. IV. Evolution of vapor-phase protection in the light of patent literature, Int. J. Corros. Scale Inhib., 2013, 2, no. 3, 162-193.

7. P.B. Raja, M. Ismail, S. Ghoreishiamiri, J. Mirza, M.C. Ismail, S. Kakooei and A.A. Rahim, Reviews on corrosion inhibitors: a short view, Chem. Eng. Commun., 2016, 203, no. 9, 1145-1156. doi: $10.1080 / 00986445.2016 .1172485$

8. V.S. Saji, A Review on Recent Patents in Corrosion Inhibitors, Recent Pat. Corros. Sci., 2010, 2, 6-12. doi: $10.2174 / 1877610801002010006$

9. F.A. Ansari, C. Verma, Y.S. Siddiqui, E.E. Ebenso and M.A. Quraishi, Volatile corrosion inhibitors for ferrous and non-ferrous metals and alloys: A review, Int. J. Corros. Scale Inhib., 2018, 7, no. 2, 126-150. doi: 10.17675/2305-6894-2018-7-2-2

10. S. Gangopadhyay and P.A. Mahanwar, Recent developments in the volatile corrosion inhibitor (VCI) coatings for metal: a review, J. Coat. Technol. Res., 2018, 15, no. 4, 789807. doi: $\underline{10.1007 / \mathrm{s} 11998-017-0015-6}$ 
11. L.G. Kolyada, E.V. Tarasyuk and S.A. Krylova, Modern packaging materials for steel products, Solid State Phenom., 2017, 265, 1040-1047. doi: 10.4028/www.scientific.net/ $\underline{\text { SSP.265. } 1040}$

12. N.N. Andreev, O.A. Goncharova, Yu.I. Kuznetsov and A.Yu. Luchkin, Method for protection of metals from atmospheric corrosion, RF Patent 264935402.04 .2018 (in Russian).

13. A.Yu. Luchkin, O.A. Goncharova, N.N. Andreev and Yu.I. Kuznetsov, New method for protection of metals from atmospheric corrosion, Prakt. Protivokorroz. Zashch., 2017, 4, 4-7 (in Russian).

14. O.A. Goncharova, A.Yu. Luchkin, Yu.I. Kuznetsov, N.N. Andreev, N.P. Andreeva and S.S. Vesely, Octadecylamine, 1,2,3-benzotriazole and a mixture thereof as chamber inhibitors of steel corrosion, Int. J. Corros. Scale Inhib., 2018, 7, no. 2, 203-212. doi: $10.17675 / 2305-6894-2018-7-2-7$

15. O.A. Goncharova, A.Yu. Luchkin, I.A. Archipushkin, N.N. Andreev, Yu.I. Kuznetsov and S.S. Vesely, Vapor-phase protection of steel by inhibitors based on salts of higher carboxylic acids, Int. J. Corros. Scale Inhib., 2019, 8, no. 3, 568-599. doi: 10.17675/2305-6894-2019-8-3-9

16. O.A. Goncharova, Yu.I. Kuznetsov, N.N. Andreev, A.Yu. Luchkin, N.P. Andreeva and D.S. Kuznetsov, A new corrosion inhibitor for zinc chamber treatment, Int. J. Corros. Scale Inhib., 2018, 7, no. 3, 340-351. doi: 10.17675/2305-6894-2018-7-3-5

17. O.A. Goncharova, A.Yu. Luchkin, N.N. Andreev, N.P. Andreeva and S.S. Vesely, Triazole derivatives as chamber inhibitors of copper corrosion, Int. J. Corros. Scale Inhib., 2018, 7, no. 4, 657-672. doi: 10.17675/2305-6894-2018-7-4-12

18. O.A. Goncharova, N.N. Andreev, A.Yu. Luchkin, Yu.I. Kuznetsov, N.P. Andreeva and S.S. Vesely, Protection of copper by treatment with hot vapours of octadecylamine, 1,2,3-benzotriazole and their mixtures, Mater. Corros., 2019, 70, no. 1, 16-68. doi: $10.1002 / \mathrm{maco} .201810366$

19. O.A. Goncharova, D.S. Kuznetsov, N.N. Andreev, Yu.I. Kuznetsov, N.P. Andreeva and S.S. Vesely, Corrosion screening of chamber inhibitors for an aluminum alloy, Int. J. Corros. Scale Inhib., 2019, 8, no. 2, 257-267. doi: 10.17675/2305-6894-2019-8-2-7

20. D.S. Kuznetsov, O.A. Goncharova, N.N. Andreev, N.P. Andreeva and S.S. Vesely, IFKhAN-140, a chamber corrosion inhibitor for brass, Int. J. Corros. Scale Inhib., 2020, 9, no. 1, 300-312. doi:10.17675/2305-6894-2020-9-1-19

21. O.A. Betretdinova, A.Yu. Luchkin, O.A. Goncharova, Yu.I. Kuznetsov, N.N. Andreev and S.S. Vesely, Criteria of additivity in the protective effect of components of mixed corrosion inhibitors in the chamber protection of zinc and steel, Int. J. Corros. Scale Inhib., 2020, 9, no. 2, 771-779. doi: 10.17675/2305-6894-2020-9-2-24

22. GOST 380-2005. Carbon steel of ordinary quality (Brands) (in Russian). 